\title{
Mechanical and thermal stability of retained austenite in plastically deformed bainite-based TRIP-aided medium-Mn steels
}

\author{
Aleksandra Kozłowska ${ }^{1}$ - Adam Grajcarr $^{1} \cdot$ Aleksandra Janik $^{2} \cdot \mathrm{Krzysztof} \mathrm{Radwański}^{2} \cdot$ Ulrich Krupp $^{3}$. \\ Krzysztof Matus ${ }^{1,4} \cdot$ Mateusz Morawiec ${ }^{1,4}$
}

Received: 25 May 2021 / Revised: 25 May 2021 / Accepted: 8 August 2021 / Published online: 18 August 2021

(c) The Author(s) 2021

\begin{abstract}
Advanced medium-Mn sheet steels show an opportunity for the development of cost-effective and light-weight automotive parts with improved safety and optimized environmental performance. These steels utilize the strain-induced martensitic transformation of metastable retained austenite to improve the strength-ductility balance. The improvement of mechanical performance is related to the tailored thermal and mechanical stabilities of retained austenite. The mechanical stability of retained austenite was estimated in static tensile tests over a wide temperature range from $20{ }^{\circ} \mathrm{C}$ to $200{ }^{\circ} \mathrm{C}$. The thermal stability of retained austenite during heating at elevated temperatures was assessed by means of dilatometry. The phase composition and microstructure evolution were investigated by means of scanning electron microscopy, electron backscatter diffraction, X-ray diffraction and transmission electron microscopy techniques. It was shown that the retained austenite stability shows a pronounced temperature dependence and is also stimulated by the manganese addition in a 3-5\% range.
\end{abstract}

Keywords Hot-rolled sheet $\cdot$ Advanced medium-Mn steel $\cdot$ Plastic deformation $\cdot$ Retained austenite $\cdot$ Strain-induced martensite $\cdot$ Phase transformation

\section{Introduction}

The metastable retained austenite is a crucial microstructural constituent enhancing mechanical properties of advanced steels by the transformation-induced plasticity (TRIP) effect [1]. The retained austenite is the essential constituent in multiphase high-strength steels, which increases strength without compromising in elongation [2]. The strain-induced martensitic transformation of dispersed retained austenite (RA) has a beneficial effect on the work-hardening behavior and

Aleksandra Kozłowska

aleksandra.kozlowska@polsl.pl

1 Department of Engineering Materials and Biomaterials, Silesian University of Technology, 18a Konarskiego Street, 44-100 Gliwice, Poland

2 Łukasiewicz Research Network-Institute for Ferrous Metallurgy, 12-14 K. Miarki Street, 44-100 Gliwice, Poland

3 Steel Institute, RWTH Aachen University, Intzestraße 1, 52-072 Aachen, Germany

4 Materials Research Laboratory, Silesian University of Technology, 18a Konarskiego Street, 44-100 Gliwice, Poland leads to retardation of necking [3]. The effectiveness of the TRIP effect is related to the amount and stability of the RA [4]. The resistance of RA to the martensitic transformation during deformation, which is known as its mechanical stability, is an important determinant of the use of TRIP steels for advanced automotive applications [5]. The gradual transformation of metastable retained austenite into the straininduced martensite during straining provides an excellent strength-ductility balance [6].

The stability of dispersely distributed retained austenite depends on numerous internal and external factors [7]. The internal factors are related to the structural features of the alloy [8], such as chemical composition (mainly $\mathrm{C}$ and Mn contents) [9], austenite grain size [10], its morphology [11] and a type of surrounding structural constituents (ferrite, bainite or martensite) [12]. The RA can be stabilized through carbon or manganese diffusion, which leads to the reduction of $\mathrm{M}_{\mathrm{s}}$ temperature [13]. When the RA contains a low carbon content, it transforms into martensite even at small strains, which results in the reduced work-hardening rate. On the other hand, high carbon content results in the austenite's overstabilization, which causes a reduction in ductility [9]. 
The external factors affecting the stability of the $\gamma$ phase are associated with processing and service conditions of steel products such as deformation temperature [14], strain rate [15], and stress state [16]. During forming operations, the temperature of steel sheets locally increases due to friction with tools and adiabatic heating of the deformed sheet. Pereira et al. [17] reported that a die temperature during a single stamping operation of DP780 and HSLA400 steels can reach $180^{\circ} \mathrm{C}$, whereas the blank can be heated to ca. $110{ }^{\circ} \mathrm{C}$. Due to higher strength properties of the TRIP steels, it is necessary to apply greater forces during the forming operation. Hence, even higher temperatures can be expected [18]. The importance of temperature influence also extends to crash events, where the ability to energy absorption is related to the temperature-dependent deformation behavior of steel [19]. It is documented in literature that the stability of RA gradually increases with increasing deformation temperature. The available studies concern mainly the high-Mn TRIP/TWIP steels [20]. Several studies deal with multiphase TRIP-aided steels composed of ferrite, bainite and metastable retained austenite [21].

The mechanical and thermal stability of RA is a crucial parameter, which should be considered during designing the chemical composition and processing conditions of the TRIP-aided steels. Understanding the factors affecting the stability of retained austenite is very important for the explanation of temperature-driven phase transformations and related issues. The optimization of the RA stability in multiphase steels still requires detailed investigations. So far, the issue was properly covered for the 1st and 2 nd generations of AHSS (Advanced High Strength Steels). The problem needs to be resolved in advanced multiphase alloys with intermediate $\mathrm{Mn}$ contents. Therefore, the present study was performed to determine the effect of the temperature in a range between $20{ }^{\circ} \mathrm{C}$ and $200{ }^{\circ} \mathrm{C}$ on the stability of dispersed retained austenite in the ferrous alloys containing 3\% and 5\% Mn.

\section{Materials and experimental methods}

\subsection{Materials and processing parameters}

Investigations were performed on two thermomechanically processed TRIP-aided iron alloys with two different manganese contents. The chemical compositions are listed in Table 1. To suppress carbide precipitation during the bainitic transformation, the steels were alloyed by silicon and aluminum [22]. The increased Mn content was applied to reduce the $\mathrm{M}_{\mathrm{s}}$ temperature. $\mathrm{Nb}$ and Ti microadditions were intended to increase the strength through grain refinement. Mo was added for solid solution strengthening.

The alloys were melted in a vacuum induction furnace (Balzers VSG-50). After hot forging to a thickness of $22 \mathrm{~mm}$, the ingots were roughly hot-rolled in a decreasing temperature range from $1200{ }^{\circ} \mathrm{C}$ to $900{ }^{\circ} \mathrm{C}$ to a thickness of $9 \mathrm{~mm}$. The next step consisted of the final thermomechanical rolling in 3 passes at deformation temperatures: $1050{ }^{\circ} \mathrm{C}$, $950{ }^{\circ} \mathrm{C}$ and $850^{\circ} \mathrm{C}$. The applied strain rate was $\sim 5 \mathrm{~s}^{-1}$. The final sample thickness was ca. $4.5 \mathrm{~mm}$. Hot rolling was realized using the semi-industrial line at Institute for Ferrous Metallurgy, Gliwice, Poland. A roll diameter of $550 \mathrm{~mm}$ and a roll barrel length of $700 \mathrm{~mm}$ were used. The detailed description of the line can be found in [23].

Following hot rolling, the $3 \mathrm{Mn}$ steel sheets were cooled at a rate of $10{ }^{\circ} \mathrm{C} / \mathrm{s}$ to $700{ }^{\circ} \mathrm{C}$ and held at this temperature within $15 \mathrm{~s}$. Then, samples were cooled at a rate of $27{ }^{\circ} \mathrm{C} / \mathrm{s}$ to the isothermal holding temperature of $400{ }^{\circ} \mathrm{C}$ at the bainitic transformation range and held at this temperature for $300 \mathrm{~s}$ followed by air cooling. In the case of the alloy containing $5 \% \mathrm{Mn}$, the test sheets were cooled directly from the final hot-rolling temperature to an isothermal holding temperature of $400{ }^{\circ} \mathrm{C}$. The cooling and isothermal holding conditions were the same like the ones applied for the $3 \mathrm{Mn}$ steel. The modification of the cooling route was applied to utilize the Mn addition for the particular steel grades.

\subsection{Mechanical testing}

Static tensile tests were performed using the INSTRON 1195 universal testing machine equipped with an environmental chamber. The tests were conducted at room $\left(20^{\circ} \mathrm{C}\right)$ and elevated $\left(60{ }^{\circ} \mathrm{C}, 100{ }^{\circ} \mathrm{C}, 140{ }^{\circ} \mathrm{C}\right.$ and $\left.200{ }^{\circ} \mathrm{C}\right)$ temperatures. Prior to testing, the samples were soaked for $30 \mathrm{~min}$ at elevated temperatures, and then they were deformed in tensile tests. The nominal strain rate of $10^{-3} \mathrm{~s}^{1}$ was applied. The tensile specimens were machined from the thermomechanically processed sheets parallel to the rolling direction. Three tensile samples for each variant with $50 \mathrm{~mm}$ gauge length and $12.5 \mathrm{~mm}$ width were used. The thickness of tensile samples was $4.5 \mathrm{~mm}$. The tensile tests were performed in accordance with the requirements of the ASTM standard [24].
Table 1 Chemical composition of the alloys (in wt.\%)

\begin{tabular}{llllllllll}
\hline Alloy type & $\mathrm{C}$ & $\mathrm{Mn}$ & $\mathrm{Si}$ & $\mathrm{Al}$ & $\mathrm{Mo}$ & $\mathrm{P}$ & $\mathrm{S}$ & $\mathrm{Nb}$ & $\mathrm{N}$ \\
\hline $3 \mathrm{Mn}$ & 0.17 & 3.1 & 0.22 & 1.6 & 0.22 & 0.008 & 0.005 & 0.040 & 0.0046 \\
$5 \mathrm{Mn}$ & 0.17 & 5.0 & 0.21 & 1.5 & 0.20 & 0.008 & 0.005 & 0.030 & 0.0054 \\
\hline
\end{tabular}




\subsection{Microstructural examination}

Different microstructural techniques were applied to reveal structural features and morphological details of the investigated steels. A scanning electron microscope (SEM) equipped with EBSD device was applied. The morphology of structural constituents was assessed using transmission electron microscopy (TEM). The microstructures were revealed using 3\% nital in the FEI Inspect F scanning electron microscope. The energy used for the analysis was $15 \mathrm{keV}$ and the working distance was $10 \mathrm{~mm}$.

The EBSD analysis was performed using a high-resolution JEOL JSM 7200F scanning electron microscope. The EBSD characterization included the scanning of different maps (low-angle and high-angle grain boundary maps, indexing quality IQ maps, phase maps, inverse pole figure IPF maps). A step size of $0.025 \mu \mathrm{m}$ was applied. The samples were prepared by mechanical grinding, followed by electrolytic polishing using a TenuPol-5 device working at a voltage of $17 \mathrm{kV}$ for $30 \mathrm{~s}$. The A3 electrolyte by Struers at a temperature $0{ }^{\circ} \mathrm{C}$ was used. TEM lamellae obtained by focused ion beam (FIB) milling were examined using a FEI Titan 80-300 S/TEM operating at an accelerating voltage of $300 \mathrm{kV}$.

\subsection{Retained austenite examination}

An Empyrean PANalytical diffractometer with $\mathrm{Co}-\mathrm{K}_{\alpha}$ anode and an iron filter in configuration with a Pixcel detector was applied. The amount of retained austenite and its lattice parameter were determined. A tube voltage of $40 \mathrm{kV}$ and a tube current of $30 \mathrm{~mA}$ were applied. The samples were processed with $0.02626^{\circ}$ step and scanned over $46^{\circ}-105^{\circ}$ angle range. Integrated intensities of the $(110) \alpha,(002) \alpha,(211) \alpha$ peaks and (111) $\gamma,(002) \gamma,(220) \gamma$ and (311) $\gamma$ were used to estimate the amount of RA. The volume fraction of the retained austenite $\mathrm{V}_{\gamma}$ was calculated using the Averbach-Cohen method [25]. The average carbon content in RA ( $\mathrm{C}_{\gamma}$ in wt. \%) was calculated by Eq. (1) taking into account major alloying elements in steels, i.e., $\mathrm{Mn}$ and $\mathrm{Al}[26]$ :

$a_{\gamma}=3.556+0.0453 \mathrm{C}_{\gamma}+0.00095 \mathrm{Mn}+0.0056 \mathrm{Al}$,

where $a_{\gamma}$ is the lattice constant $(\AA)$ of the austenite measured by XRD, $\mathrm{C}_{\gamma}, \mathrm{Mn}$ and $\mathrm{Al}$, are the contents (wt.\%) of carbon in retained austenite and manganese and aluminum in the alloy, respectively.

Thermal stability of retained austenite was assessed using dilatometric measurements. The kinetics of phase transformation during tempering at $140{ }^{\circ} \mathrm{C}$ and $200{ }^{\circ} \mathrm{C}$ within 30 min was characterized using high-resolution BÄHR dilatometer DIL805A/D with induction heating of the samples in vacuum. The time corresponded to the one applied during tensile testing. The samples with dimensions of $4 \mathrm{~mm}$ diameter and $10 \mathrm{~mm}$ in length were machined for the dilatometric analysis. The cooling was conducted using helium.

\section{Results}

\subsection{Microstructures in the initial state}

\subsubsection{SEM observations}

The matrix of $3 \mathrm{Mn}$ alloy is composed of fine bainitic ferrite, dispersely distributed retained austenite and some fraction of martensite (Fig. 1a). Layers of retained austenite embedded in bainitic ferrite and martensitic-austenitic (MA) constituents can be distinguished. MA constituents were formed as a result of a partial martensitic transformation of blocky RA grains, which took place during the final cooling of the steel to room temperature. It is associated with a lower carbon content in blocky-type austenite grains compared to the thin
Fig. 1 Microstructures of investigated alloys in the initial state (after hot rolling) a $3 \mathrm{Mn}$ and $\mathbf{b}$ $5 \mathrm{Mn} ; R A$ retained austenite, $M$ martensite, $M A$ martensitic-austenitic constituents
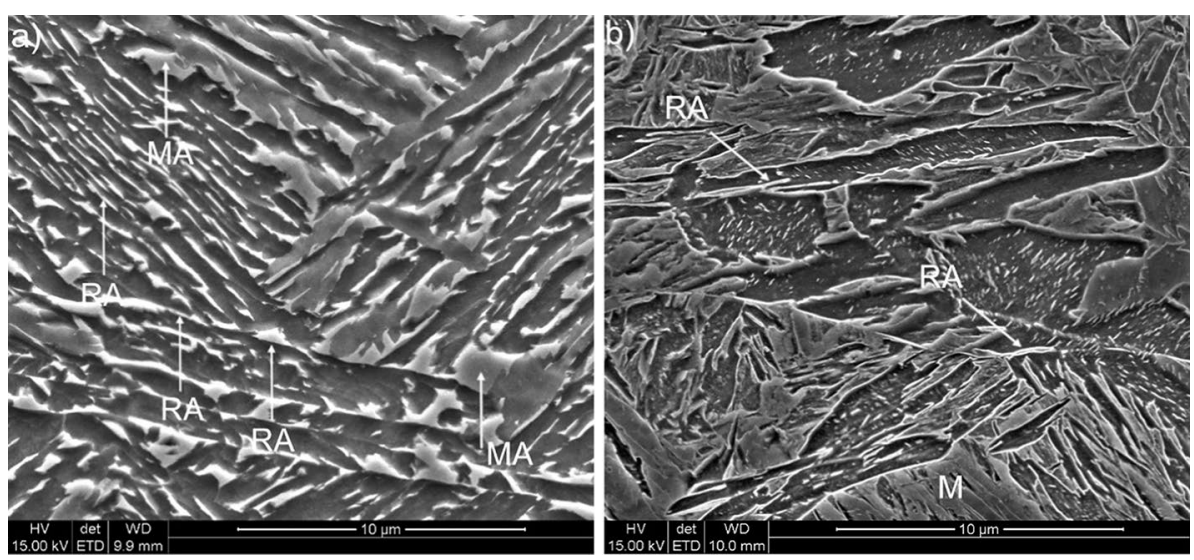
layers RA [27]; therefore, they were characterized by different local $\mathrm{M}_{\mathrm{s}}$ temperatures.

$5 \mathrm{Mn}$ alloy microstructure consists of bainitic ferrite laths, martensite areas and thin layers of retained austenite located among them (Fig. 1b). The amount of RA is lower than in the steel containing 3\% Mn. This is due to the lower thermodynamic stability of the RA resulting from a lower carbon enrichment [28]. Small precipitates characterized by a various shape can be observed inside the bainitic areas.

\subsubsection{EBSD analysis}

Figures 2 and 3 show different types of EBSD maps. Retained austenite occurs as dark areas characterized by a low value of the IQ parameter (Figs. 2a and 3a). The darkest areas are represented by martensite due to its highest dislocation density [29]. It can be seen that for the undeformed alloy containing $5 \% \mathrm{Mn}$, more MA areas were identified when compared to $3 \% \mathrm{Mn}$ type steel (Figs. 2a and 3a). It is reflected in a higher fraction of areas characterized by the low diffraction quality (a low value of the IQ parameter). Figures $2 b$ and $3 b$ show the RA distribution (marked in green). The red color corresponds to microstructural constituents with bcc lattice (ferrite, bainite, martensite). Dispersed RA occurs as thin layers located between the bainitic ferrite laths and in martensitic areas (Figs. $2 b$ and $3 b$ ). The fraction of RA estimated by EBSD for 3Mn steel was 8.3\%. The local amount of RA in steel with the higher manganese content (Fig. 3b) is smaller than in the alloy with the lower Mn content.

In both investigated alloys, the occurrence of high-angle grain boundaries (misorientation angle $>15^{\circ}$ ) marked as blue is predominant (Figs. 2c and 3c). Retained austenite occurs in the high-angle grain boundary areas. Inverse pole figure maps show that the RA grains exhibit various crystallographic orientations (Figs. 2d and 3d). However, some RA grains in $5 \mathrm{Mn}$ steel show the privileged crystallographic orientation in the $<111>$ direction.
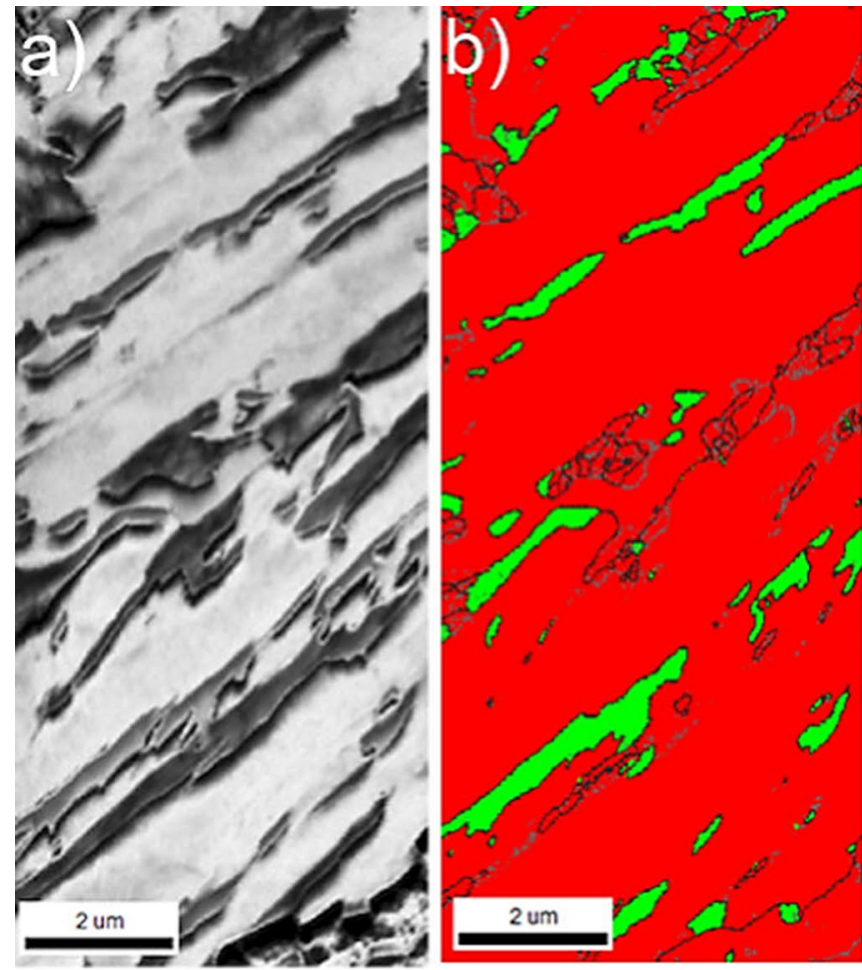

Color Coded Mlap Type: Phase

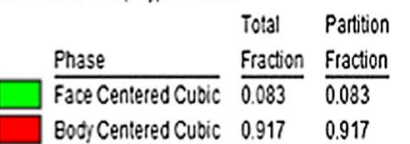

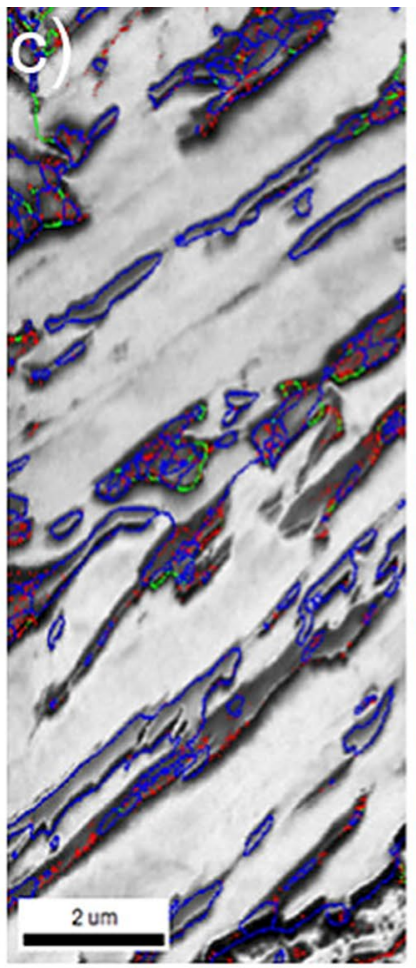

Bourdsiles: Rolation Arot:

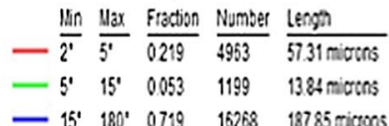

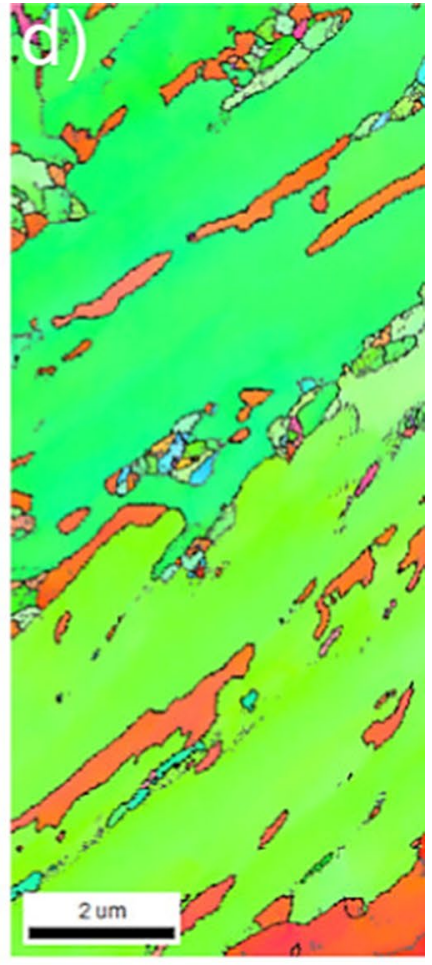

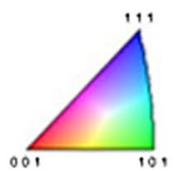

Fig. 2 EBSD maps of 3Mn alloy in the initial state: a image quality map, b phase distribution map-retained austenite (RA) as green, $\mathbf{c}$ lowangle boundary $\left(<15^{\circ}\right.$-as red and green lines $)$ and high-angle boundary $\left(>15^{\circ}\right.$-as blue lines $), \mathbf{d}$ inverse pole figure map 


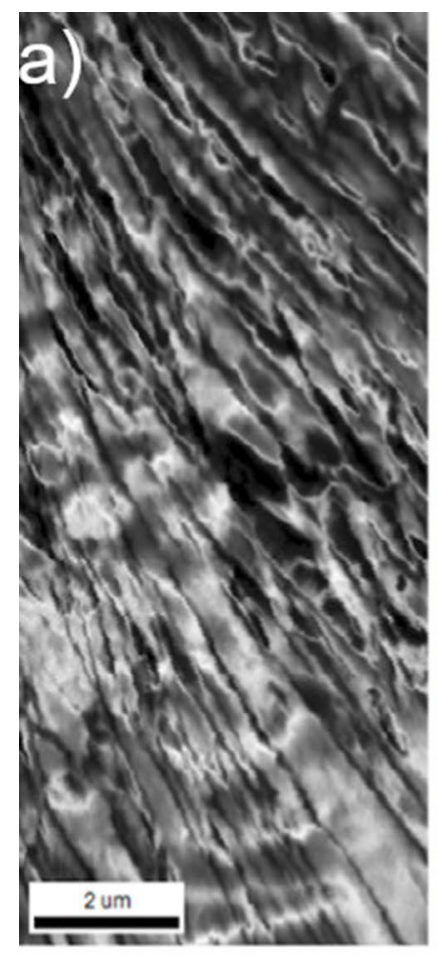

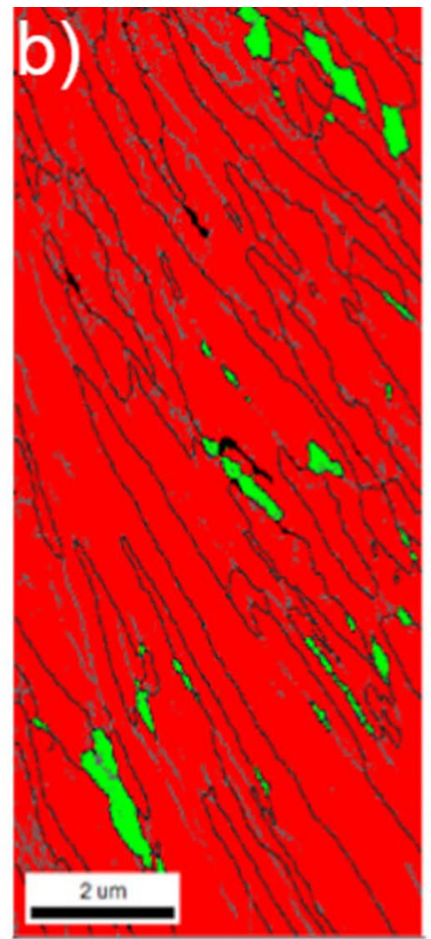

Color Coded Mop Type: Phase

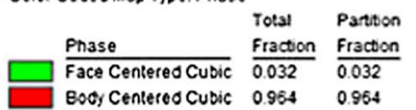

Body Centereod Cubic $0.984 \quad 0.964$

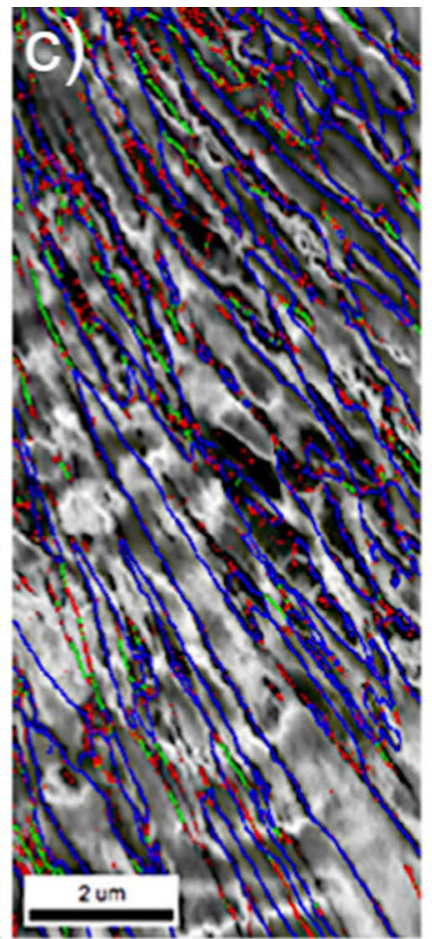

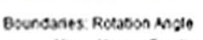

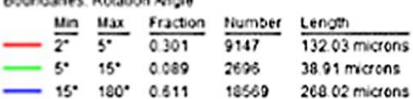

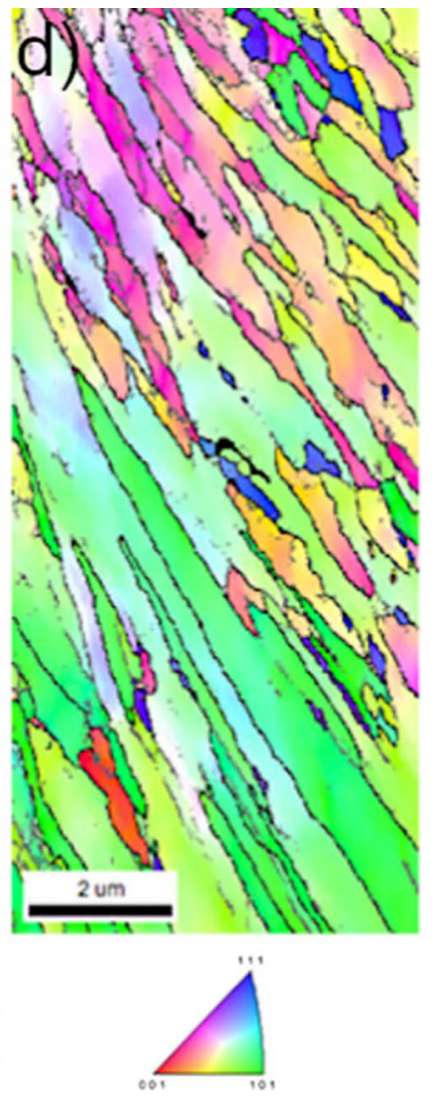

Fig. 3 EBSD maps of 5Mn alloy in the initial state: a image quality map, b phase distribution map-retained austenite (RA) as green, $\mathbf{c}$ lowangle boundary $\left(<15^{\circ}\right.$ - as red and green lines $)$ and high-angle boundary $\left(>15^{\circ}\right.$ - as blue lines $)$, $\mathbf{d}$ inverse pole figure map

\subsection{Microstructures at different temperatures}

\subsubsection{SEM observations}

Representative microstructures of the investigated steels deformed at selected deformation temperatures, $20{ }^{\circ} \mathrm{C}$ and $200{ }^{\circ} \mathrm{C}$, are presented in Fig. 4. RA and strain-induced martensite can be observed. Almost all fraction of dispersed blocky-type RA transformed into martensite during straining. A small fraction of RA in the form of thin layers stayed stable. The central part of the austenitic grains transformed into martensite, whereas the outer areas remained stable. This is attributed to a higher carbon content in the austenite grain boundaries, which results in their greater stability [5].

An increase in deformation temperature to $200{ }^{\circ} \mathrm{C}$ resulted in the higher mechanical stability of RA (Fig. 4c and d). A slightly higher fraction of untransformed RA can be observed in the microstructures of the samples deformed at the highest temperature, when compared to the microstructures obtained at the lower deformation temperature (Fig. 4a and b). The investigated steels possess some fraction of RA located between bainitic laths and in outer areas of blocky grains of this phase.

\subsubsection{XRD analysis}

XRD analysis was performed to quantitatively analyze the temperature-dependent mechanical stability of RA. The determined volume fraction of RA and its $\mathrm{C}$ content are listed in Table 2. In general, the RA amount increased with increasing deformation temperature. The lowest amount of RA stayed stable in the specimen deformed at $20{ }^{\circ} \mathrm{C}$, whereas the highest fraction of RA was detected in the specimen deformed at the highest temperature $\left(200{ }^{\circ} \mathrm{C}\right)$. It was due to a gradual increase in the mechanical stability of dispersed RA with increasing the deformation temperature. A small fraction of untransformed austenite was detected in the $5 \mathrm{Mn}$ steel deformed at $100{ }^{\circ} \mathrm{C}, 140{ }^{\circ} \mathrm{C}$ and $200{ }^{\circ} \mathrm{C}$ : $2.6 \%, 2.9 \%$ and $3.4 \%$, respectively. Almost, all fraction of RA undergoes martensitic transformation in a temperature range from $20^{\circ} \mathrm{C}$ to $60{ }^{\circ} \mathrm{C}$. This means that the mechanical stability of RA in the steel containing $5 \% \mathrm{Mn}$ was lower when compared to the $3 \mathrm{Mn}$ steel.

In addition to the temperature effect, the mechanical stability of RA is also affected by a chemical composition, especially a carbon content in this phase. An increase in the carbon content in RA results in the higher stability of 
Fig. 4 SEM micrographs of the investigated alloys deformed at selected temperatures: $20^{\circ} \mathrm{C}-\mathbf{a}$ $3 \mathrm{Mn}$ and $\mathbf{b} 5 \mathrm{Mn} ; 200{ }^{\circ} \mathrm{C}-\mathbf{c}$ $3 \mathrm{Mn}$ and $\mathbf{d} 5 \mathrm{Mn}$

Table 2 Quantitative details of retained austenite examination
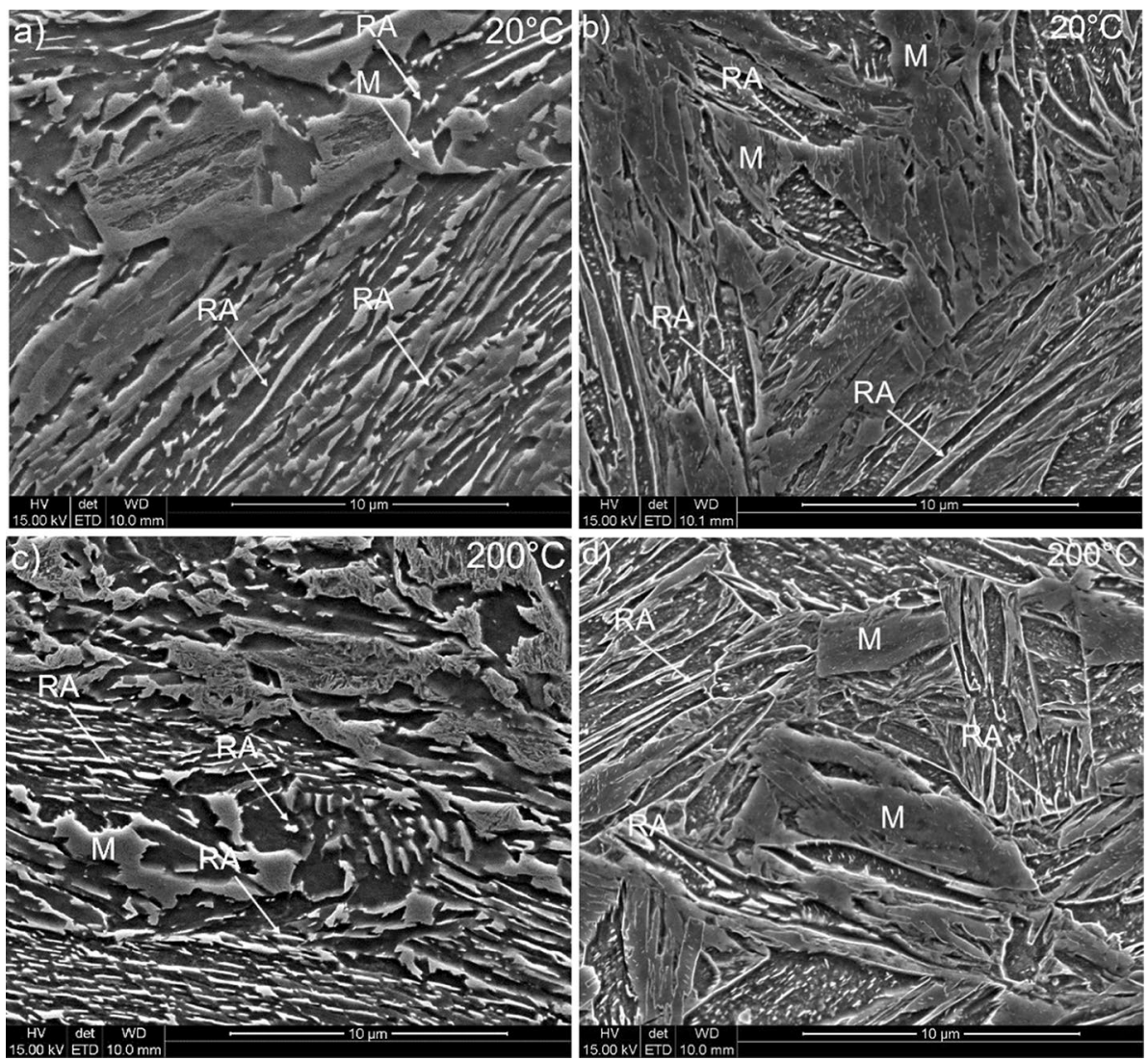

\begin{tabular}{|c|c|c|c|c|}
\hline \multirow{2}{*}{$\begin{array}{l}\text { Deformation tem- } \\
\text { perature }\left({ }^{\circ} \mathrm{C}\right)\end{array}$} & \multicolumn{2}{|l|}{$3 \mathrm{Mn}$} & \multicolumn{2}{|l|}{$5 \mathrm{Mn}$} \\
\hline & $\begin{array}{l}\text { Volume fraction of } \\
\text { RA, }(\%)\end{array}$ & $\begin{array}{l}\text { Carbon content in } \\
\text { RA (wt.\%) }\end{array}$ & $\begin{array}{l}\text { Volume fraction of } \\
\text { RA, }(\%)\end{array}$ & $\begin{array}{l}\text { Carbon } \\
\text { content in RA } \\
(\text { wt. } \%)\end{array}$ \\
\hline Initial state & $12.1 \pm 1.9$ & $1.10 \pm 0.09$ & $8.0 \pm 1.4$ & $0.92 \pm 0.09$ \\
\hline 20 & $2.7 \pm 0.5$ & $1.15 \pm 0.08$ & $<2$ & - \\
\hline 60 & $5.9 \pm 0.9$ & $1.08 \pm 0.10$ & $<2$ & - \\
\hline 100 & $7.8 \pm 0.2$ & $1.05 \pm 0.04$ & $2.6 \pm 0.2$ & $0.99 \pm 0.06$ \\
\hline 140 & $9.3 \pm 0.8$ & $1.04 \pm 0.07$ & $2.9 \pm 0.4$ & $0.96 \pm 0.08$ \\
\hline 200 & $10.5 \pm 1.0$ & $1.07 \pm 0.03$ & $3.4 \pm 0.2$ & $0.89 \pm 0.05$ \\
\hline
\end{tabular}

this phase and its lower tendency to strain-induced martensitic transformation. The $3 \mathrm{Mn}$ steel in the initial state possesses $1.1 \% \mathrm{C}$, whereas it is $0.92 \% \mathrm{C}$ in the $5 \% \mathrm{Mn}$ alloy (cf. Table 2). It resulted in a more intense partial martensitic transformation of blocky-type RA during final cooling after the hot-rolling step in 5Mn steel (Figs. 1b and 3a). The carbon in RA within samples deformed at different temperatures refers to a carbon content in the phase, which remained stable after deformation. It can be observed that in the $5 \mathrm{Mn}$ alloy deformed at the highest temperature $\left(200{ }^{\circ} \mathrm{C}\right)$, some decrease in a carbon content in RA was noted. It is due to the occurrence of thermally activated processes leading to a decrease in the carbon content. This effect is more pronounced in the case of $5 \mathrm{Mn}$ steel.

\subsubsection{EBSD analysis}

Figure 5 displays the EBSD crystallographic analyses of $3 \mathrm{Mn}$ steel deformed at selected elevated deformation temperatures: $100{ }^{\circ} \mathrm{C}$ and $200{ }^{\circ} \mathrm{C}$, respectively. An increase in the amount of dark areas characterized by low Kikuchi pattern quality (IQ) typical for dislocated martensite was observed (Fig. 5a and b), when compared to the undeformed specimen (Fig. 2a). Phase distribution maps (Fig. 5c and d) show that the specimen deformed at $200{ }^{\circ} \mathrm{C}$ possesses a 

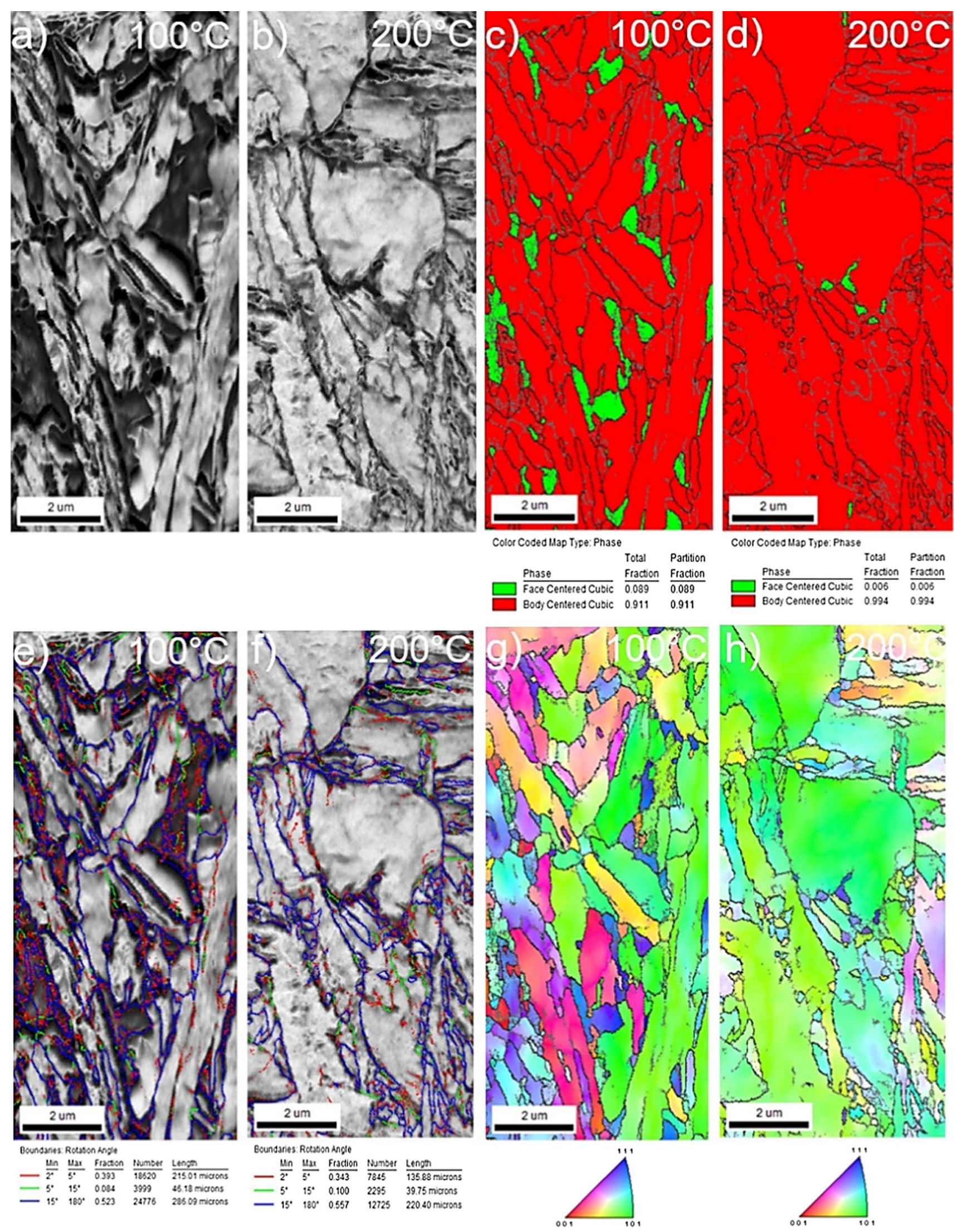

Fig. 5 EBSD maps of $3 \mathrm{Mn}$ alloy deformed at $100{ }^{\circ} \mathrm{C}$ and $200{ }^{\circ} \mathrm{C}$ : $\mathbf{a}, \mathbf{b}$ IQ maps, $\mathbf{c}, \mathbf{d}$ retained austenite (green color) maps, e, $\mathbf{f}$ misorientation angle maps, $\mathbf{g}$, $\mathbf{h}$ IPF maps 
lower fraction of RA than the specimen deformed at $100{ }^{\circ} \mathrm{C}$. Only a few small RA grains were identified at $200{ }^{\circ} \mathrm{C}$ (Fig. 5d). RA identified at $100{ }^{\circ} \mathrm{C}$ occurs in a form of layers with various thicknesses located between the bainitic ferrite laths and as small grains in martensitic areas, which were formed due to the fragmentation of larger austenite grains by newly formed martensite. Some grain coarsening can be also seen for bainitic ferrite grains at $200{ }^{\circ} \mathrm{C}$ (Fig. 5b).

The amount of low-angle grain boundaries was higher (Fig. 5e and f) when compared to the specimen in the initial state. The boundaries were formed in the austenitic-martensitic constituents [30]. Inverse pole figures (Fig. 5g and h) show that retained austenite was mainly $<111>$-oriented with respect to rolling direction.

In case of $5 \mathrm{Mn}$ steel, almost all fraction of RA transformed into martensite during straining at $100{ }^{\circ} \mathrm{C}$ and $200^{\circ} \mathrm{C}$. Thus, numerous dark areas of low diffraction quality represented by martensite can be observed (Fig. 6a and b). The presence of RA was not detected in phase distribution maps (Fig. $6 \mathrm{c}$ and d). The microstructural constituents are characterized by various crystallographic orientations independent from the deformation temperature (Fig. $6 \mathrm{~g}$ and $\mathrm{h}$ ).

\subsubsection{TEM observations}

Results obtained in the transmission electron microscope (TEM) confirm the occurrence of the TRIP effect and thermally activated processes affecting the stability of RA at elevated deformation temperatures. Figure 7 shows the results of TEM observations obtained for $3 \mathrm{Mn}$ alloy deformed at $100{ }^{\circ} \mathrm{C}$. Layers of retained austenite, which partially transformed into martensite can be observed. The central part of RA transformed into martensite (Fig. 7b and c), whereas outer areas stayed stable due to their higher carbon enrichment [5]. The presence of martensite was confirmed by selected area diffraction (SAD, Fig. 7d).

TEM observations of both investigated alloys deformed at $200{ }^{\circ} \mathrm{C}$ revealed subgrains with various sizes $(0.2-0.3 \mu \mathrm{m})$ resulting from the dynamic recovery (Fig. 8a and b). Moreover, the reduced dislocation density can be observed both in the bainitic ferrite matrix and in the non-transformed RA. In case of 5Mn alloy, the presence of fine-dispersed carbide precipitates in martensitic laths was identified (Fig. 9).

\section{Discussion}

\subsection{Effect of manganese content on the stability of retained austenite}

The metastability degree of dispersed retained austenite substantially depends on the chemical composition of this phase. The processing strategies providing the stabilization of RA are based on carbon and/or manganese enrichments [9]. In the present study, the stabilization of the $\gamma$ constituent is possible only by carbon diffusion. Stabilization through Mn partitioning has not taken place due to applied processing parameters, i.e., the investigated hot-rolled steels were cooled directly from the finishing rolling temperature to $400{ }^{\circ} \mathrm{C}$ (diffusion of $\mathrm{Mn}$ is impossible for such short times).

The results obtained for undeformed specimens showed that an increase in manganese amount from 3 to $5 \%$ leads to a reduction of the carbon content in RA from $1.1 \%$ to $0.92 \%$ (Table 2). Hojo et al. [31] observed the similar effect in Fe-0.2C-(1.5-5Mn)-1.5Si steels with a microstructure composed of martensite and retained austenite. They found that increasing the $\mathrm{Mn}$ amount from $1.5 \%$ to $3 \%$ resulted in the reduction of $\mathrm{C}$ content in the austenite from $1 \%$ to $0.7 \%$. Further increasing the $\mathrm{Mn}$ amount to $5 \%$ led to the reduction of the $\mathrm{C}$ content in RA to only $0.3 \%$. No such huge decrease in the carbon content was noted here. In the present study, RA in the steel containing $5 \% \mathrm{Mn}$ was characterized by its lower stability due to the lower $\mathrm{C}$ enrichment. Hence, some fraction of blocky-type RA (characterized by a lower $\mathrm{C}$ content than film-type RA [2]) transformed into martensite already during cooling of sheet samples. Therefore, the fraction of MA constituents in the initial state was higher than in the $3 \mathrm{Mn}$ alloy (Fig. 1).

\subsection{Thermal stability of retained austenite at elevated temperatures}

The thermal stability of retained austenite and carbide precipitation phenomena were further studied in dilatometric tests. Results of the dilatometric study (Fig. 10) show that in both alloys, $5 \mathrm{Mn}$ and $3 \mathrm{Mn}$ steel tempered at $140{ }^{\circ} \mathrm{C}$ and $200{ }^{\circ} \mathrm{C}$, respectively, the precipitation of carbides took place. In case of 5Mn steel, it can be seen that at $140{ }^{\circ} \mathrm{C}$ after approximately $700 \mathrm{~s}$ the relative change in length (RCL) started to decrease from $0.080 \%$ to $0.061 \%$. A drop in the RCL value means that the precipitation process took place in the alpha phase (martensite) [32]. A similar tendency was noted in 3Mn steel. However, the precipitation started after $1300 \mathrm{~s}$. An opposite trend was observed at $200{ }^{\circ} \mathrm{C}$ in $5 \mathrm{Mn}$ steel. In this case, the RCL increased from $0.138 \%$ to $0.153 \%$ after $450 \mathrm{~s}$. This observation confirmed that some amount of carbides were formed in RA or thermal decomposition of RA into ferrite and carbides took place [33]. Such effect was not noted for the alloy containing $3 \%$ of manganese. Therefore, it can be concluded that depending on the tempering temperature, the carbides were formed in different phases [34]. Moreover, the results of dilatometric tests confirmed that the RA in $5 \mathrm{Mn}$ steel is more sensitive to temperature than in the case of steel containing $3 \%$ manganese. The presence of cementite precipitates was also confirmed in thermodynamic calculations using JMatPro [35]. Figure 11 indicates carbide formation is predicted for both steels. Their 

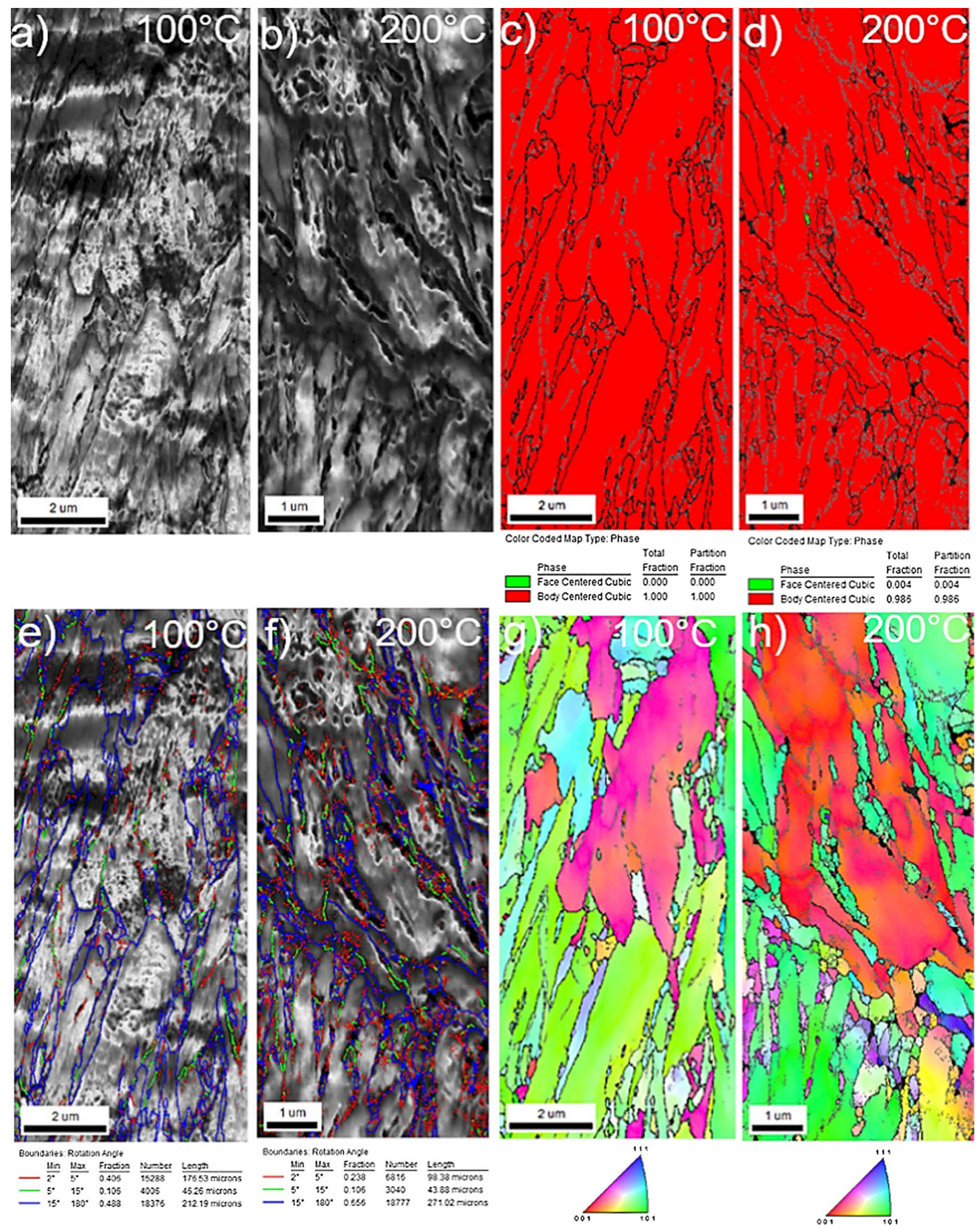

Fig. 6 EBSD maps of $5 \mathrm{Mn}$ alloy deformed at $100{ }^{\circ} \mathrm{C}$ and $200{ }^{\circ} \mathrm{C}$ : $\mathbf{a}, \mathbf{b}$ IQ maps, $\mathbf{c}, \mathbf{d}$ retained austenite (green color) maps, e, $\mathbf{f}$ misorientation angle maps, $\mathbf{g}$, $\mathbf{h}$ IPF maps 

partially transformed into deformed at $100{ }^{\circ} \mathrm{C}$ : a bright field (BF), $\mathbf{b}$ magnification of martensitic laths (BF), $\mathbf{c}$ and corresponding dark field (DF) image, $\mathbf{d}$ selected area diffraction pattern of martensitic laths
Fig. 7 Retained austenite grain martensite in the $3 \% \mathrm{Mn}$ steel
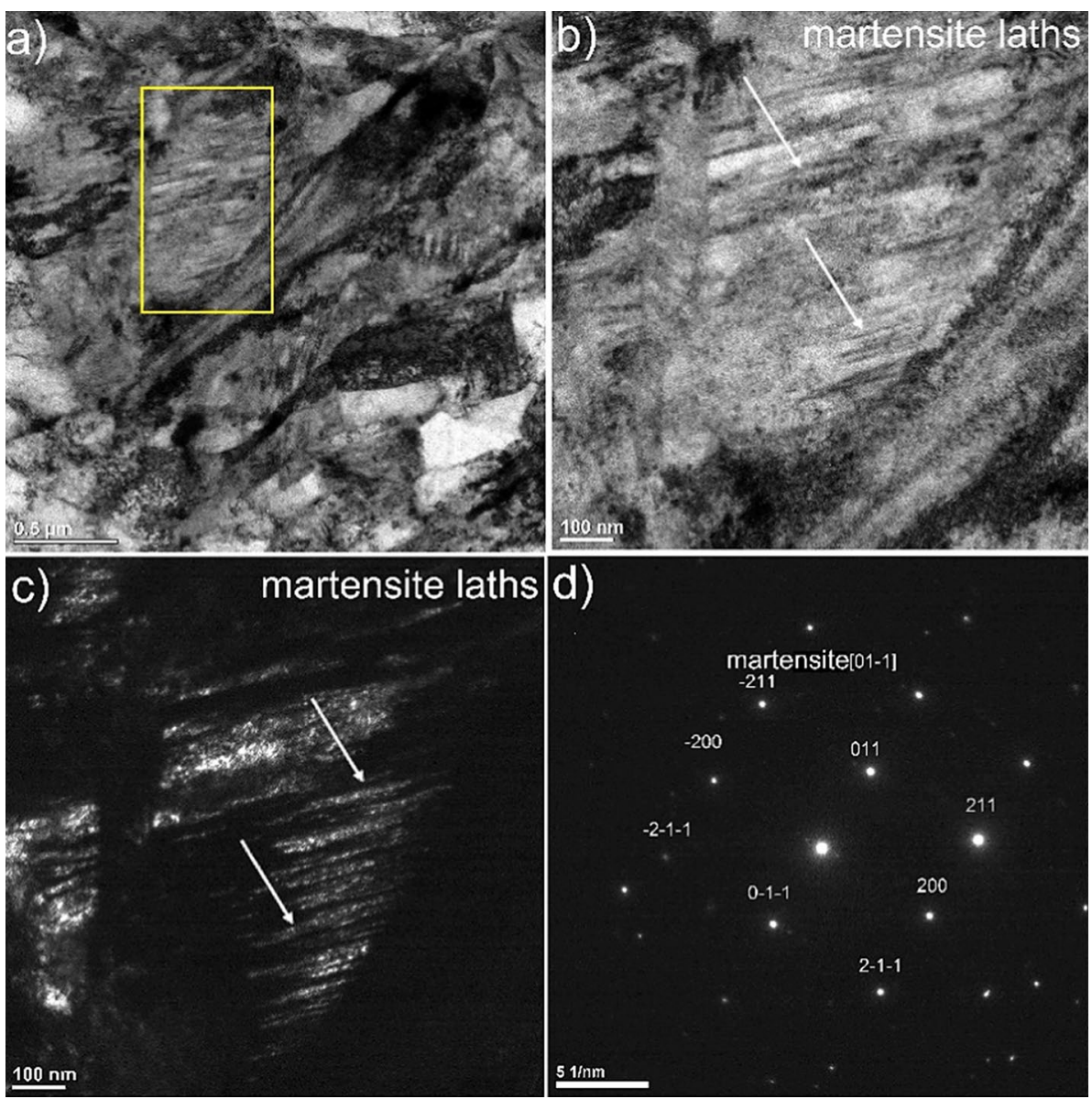

Fig. 8 a Subgrains in $3 \mathrm{Mn}$ steel and $\mathbf{b} 5 \mathrm{Mn}$ steel deformed at $200{ }^{\circ} \mathrm{C}$
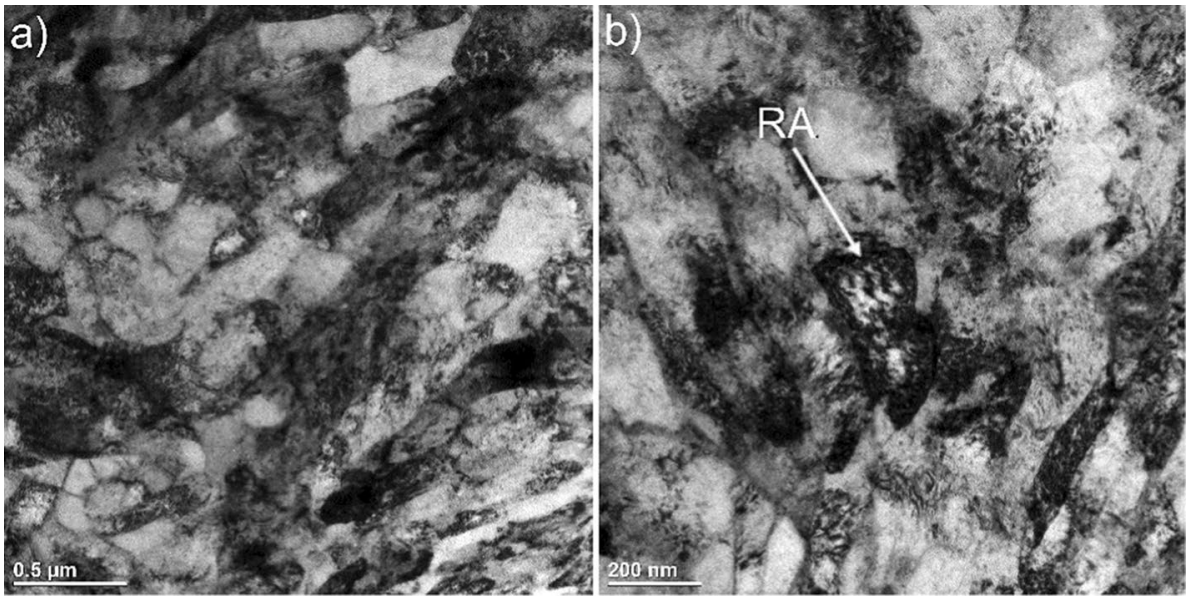

volume fractions are very similar. It is clear that the precipitation process is started at $140{ }^{\circ} \mathrm{C}$, whereas at $200{ }^{\circ} \mathrm{C}$ the precipitation is accelerated in both alloys reaching the maximum vol. \% of carbides (ca. 2.5\%) after $200 \mathrm{~s}$.

\subsection{Mechanical stability of retained austenite at different temperatures}

The microstructure evolution during plastic deformation is related to the deformation of all structural constituents. However, in TRIP-aided steels special attention is paid to the tendency of dispersely distributed retained austenite to 
Fig. 9 Carbide precipitates in martensitic laths in $5 \mathrm{Mn}$ alloy deformed at $200{ }^{\circ} \mathrm{C}$; a bright field (BF), $\mathbf{b}$ dark field (DF) of carbides, $\mathbf{c}$ selected area diffraction pattern of carbides
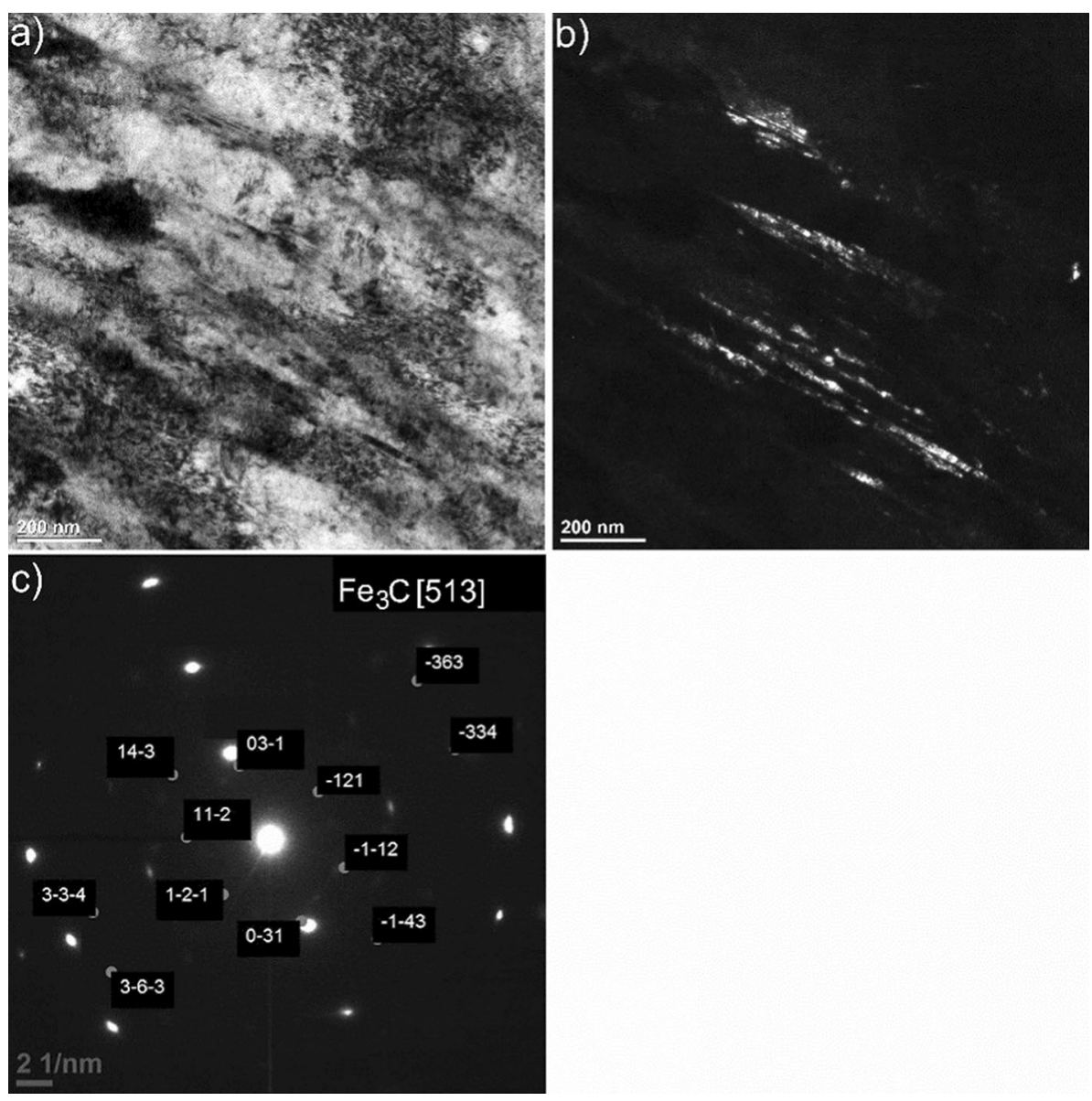

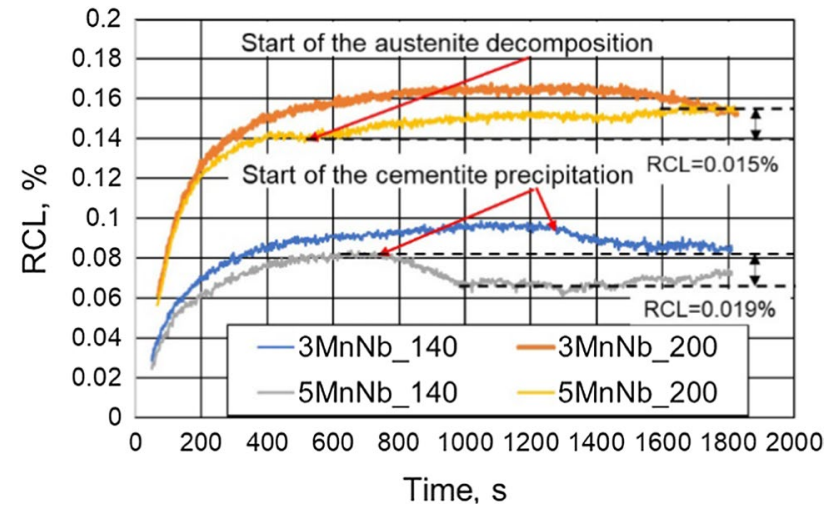

Fig. 10 The dilatometric curves of $3 \mathrm{Mn}$ and $5 \mathrm{Mn}$ alloys during tempering at $140{ }^{\circ} \mathrm{C}$ and $200{ }^{\circ} \mathrm{C}$

strain-induced martensite formation. Results of the present study show that the microstructural changes are affected by the intensity of TRIP effect and thermally activated processes occurring at the highest deformation temperatures $\left(140{ }^{\circ} \mathrm{C}\right.$ and $\left.200{ }^{\circ} \mathrm{C}\right)$.

In a temperature range from $20{ }^{\circ} \mathrm{C}$ to $100{ }^{\circ} \mathrm{C}$, the microstructure evolution during tensile deformation is mainly controlled by phase transformation of retained

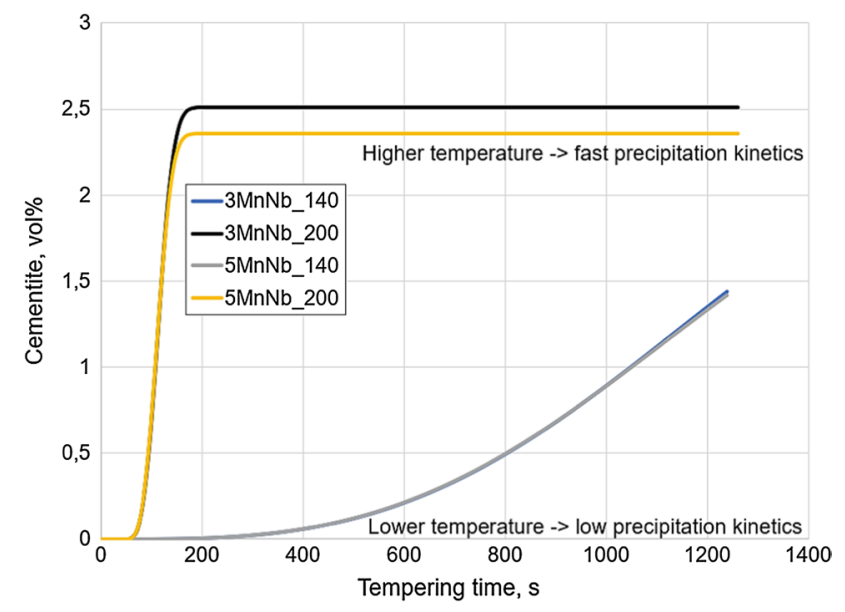

Fig. 11 Thermodynamic analysis (JMatPro) of cementite precipitation of $3 \mathrm{Mn}$ and $5 \mathrm{Mn}$ alloys during tempering at $140{ }^{\circ} \mathrm{C}$ and $200{ }^{\circ} \mathrm{C}$

austenite to strain-induced martensite. At higher deformation temperatures, an increased stability of RA was noticed (Table 2). Zhang et al. [36] reported similar results for $\mathrm{Fe}-0.12 \mathrm{C}-7 \mathrm{Mn}-0.3 \mathrm{Si}$ and $\mathrm{Fe}-0.12 \mathrm{C}-10 \mathrm{Mn}-2 \mathrm{Al}-0.05 \mathrm{Si}$ alloys with ferritic-austenitic microstructures. The same tendency was also observed in steels containing $\mathrm{Mn}$ in the 

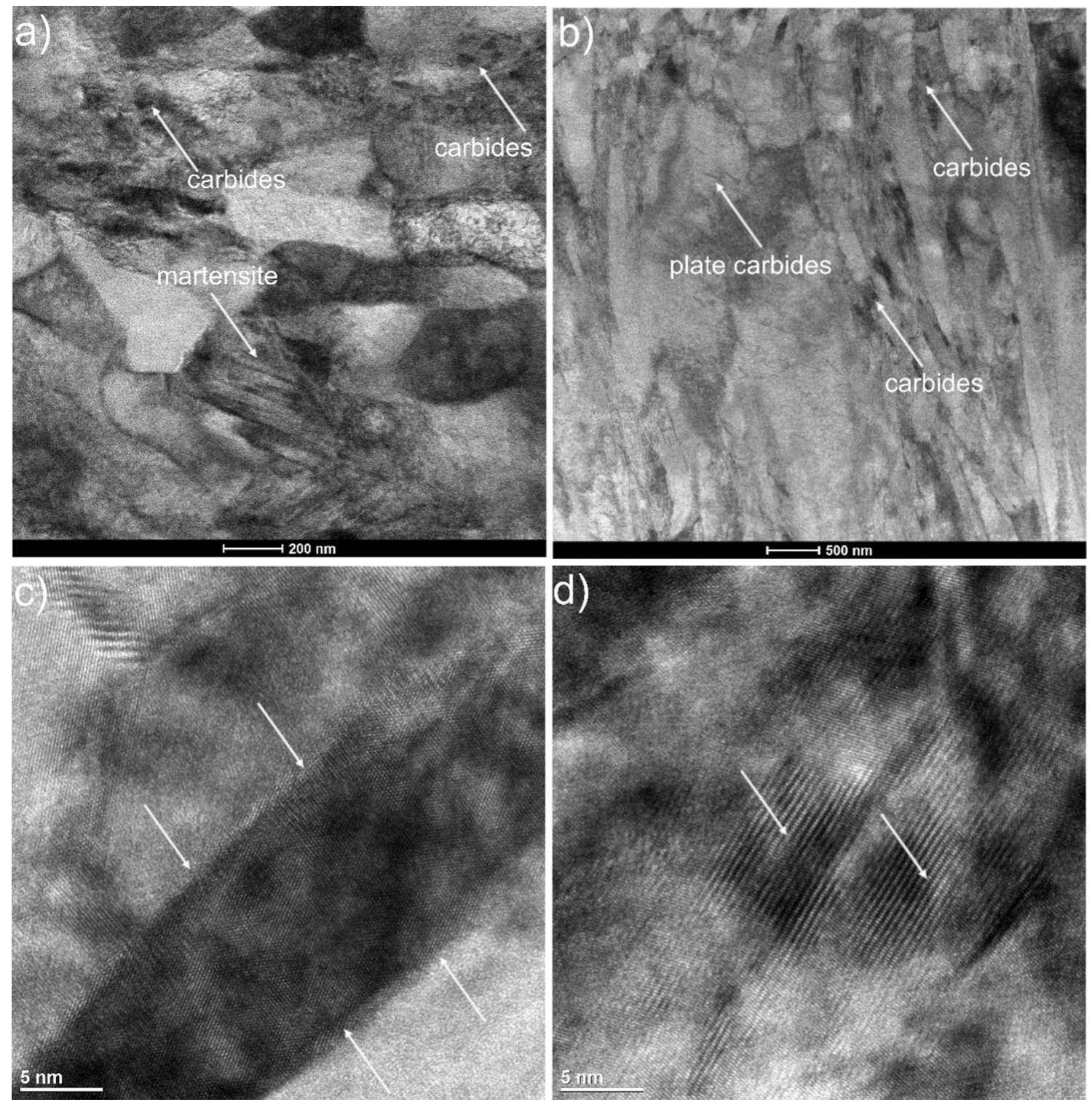

Fig. 12 TEM micrographs of the investigated alloys deformed at $200{ }^{\circ} \mathrm{C}$. a HAADF STEM: subgrains, carbide precipitates and martensitic laths in $3 \mathrm{Mn}$ steel, $\mathbf{b}$ subgrains and plate carbides in 5Mn steel; moire fringes-high-resolution TEM: c 3Mn steel and $\mathbf{d}$ 5Mn steel

range between $1.5 \%$ and 5\% [37]. This can be attributed to an increase of the stacking fault energy (SFE) value of austenite [5].

Results of the present study show that at the highest deformation temperature $\left(200^{\circ} \mathrm{C}\right)$, besides the local martensitic transformation, thermally activated processes took also place (Figs. 11 and 12). The occurrence of dynamic recovery and carbide precipitation were confirmed by the transmission electron microscopy (Fig. 12a and b). The formation of small globular grains and increased bainitic lath thickness were also revealed via EBSD method (Figs. $5 \mathrm{~h}$ and $6 \mathrm{~h}$ ). Figure $12 \mathrm{a}$ and $\mathrm{b}$ show subgrains characterized by various sizes in the range of $\sim 100-300 \mathrm{~nm}$ resulting from the dynamic recovery process. Moreover, the reduced dislocation density can be observed both in the bainitic ferrite matrix and in the untransformed retained austenite. So far, such effects have not been reported in medium manganese steels. The alloy containing $5 \% \mathrm{Mn}$ is characterized by a higher tendency to carbide precipitation (Fig. 9), which is reflected in a decrease in its carbon content in RA at the highest deformation temperature (Table 2). Moreover, some fraction of plate carbides in bainitic ferrite laths can be observed (Fig. 12b). They were also revealed using SEM in the undeformed sample (Fig. 1b). The high-resolution TEM images show the presence of Moire fringes (Fig. 12c and d), which indicates an initial stage of low-angle boundary formation (usually $<2^{\circ}$ ) [38]. Moreover, the Moire fringes revealed the increased density of dislocations at grain boundaries [39]. 
The EBSD analyses at $100{ }^{\circ} \mathrm{C}$ and $200{ }^{\circ} \mathrm{C}$ showed that deformed specimens (Figs. $5 \mathrm{e}-\mathrm{f}$ and $6 \mathrm{e}-\mathrm{f}$ ) were characterized by higher fraction of low-angle grain boundaries $\left(<15^{\circ}\right)$ compared to the samples in the initial state (Figs. 2c and 3c). It indirectly indicates a significant rise in dislocation density during deformation [40]. An increased amount of such boundaries is also due to the dynamic recovery at the highest deformation temperature (Fig. 8). However, the amount of high-angle boundaries also increases for the deformed samples due to the strain-induced martensitic transformation and resulting formation of austenite-martensite interfaces. This type of grain boundaries occurs in martensitic areas [30]. Therefore, the final distribution between low-angle and highangle boundaries is the resultant of several opposite effects.

\section{Conclusions}

The mechanical and thermal stability of retained austenite (RA) in thermomechanically processed alloys containing 3\% and 5\% Mn were reported in the present study. The microstructure evolution and intensity of thermally activated processes at elevated temperatures were characterized. The conclusions were as follows:

- The mechanical stability of retained austenite strongly depends on a deformation temperature. An increase in the temperature resulted in the reduced intensity of strain-induced transformation of retained austenite into martensite due to the higher mechanical stability of this phase attributed to corresponding rise in its SFE value.

- The microstructure evolution of investigated alloys in a temperature range from $20^{\circ} \mathrm{C}$ to $100{ }^{\circ} \mathrm{C}$ is controlled by strain-induced transformation of retained austenite into martensite. The TRIP effect plays a minor role when the deformation temperature is elevated. At the highest deformation temperature $140{ }^{\circ} \mathrm{C}$ and $200^{\circ} \mathrm{C}$ the significance of the TRIP effect decreases in favor of dynamic recovery leading to a decrease in dislocation density and subgrains formation.

- The steel containing 3\% of Mn is less susceptible to carbide precipitation and thermal decomposition than the alloy containing 5\% Mn. At the highest deformation temperature $200{ }^{\circ} \mathrm{C}$, the precipitation of carbides depletes the austenite in carbon reducing its stability.

- A lower carbon enrichment of retained austenite is observed with increasing manganese content. The retained austenite in steel containing $3 \% \mathrm{Mn}$ possesses $\sim 1.1 \% \mathrm{C}$, whereas carbon content in $\mathrm{RA}$ in $5 \mathrm{Mn}$ steel was lower $\sim 0.92 \%$.
Acknowledgements A. Kozłowska acknowledges the scientific internship at RWTH Aachen University, IEHK Steel Institute, Aachen, Germany from October to December 2020. The publication was supported under the Initiative of Excellence-Research University program implemented at the Silesian University of Technology in 2020, grant no. 10/010/SDU20/10-2701.

Data availability statement The data that support the findings of this study are available from the corresponding author upon reasonable request.

\section{Declarations}

Conflict of interest The authors declare that they have no conflict of interest.

Open Access This article is licensed under a Creative Commons Attribution 4.0 International License, which permits use, sharing, adaptation, distribution and reproduction in any medium or format, as long as you give appropriate credit to the original author(s) and the source, provide a link to the Creative Commons licence, and indicate if changes were made. The images or other third party material in this article are included in the article's Creative Commons licence, unless indicated otherwise in a credit line to the material. If material is not included in the article's Creative Commons licence and your intended use is not permitted by statutory regulation or exceeds the permitted use, you will need to obtain permission directly from the copyright holder. To view a copy of this licence, visit http://creativecommons.org/licenses/by/4.0/.

\section{References}

1. Podder AS, Bhadeshia HKDH. Thermal stability of austenite retained in bainitic steels. Mater Sci Eng A. 2010;527:2121-8. https://doi.org/10.1016/j.msea.2009.11.063.

2. Lee D, Kim JK, Lee S, Lee K, De Cooman BC. Microstructures and mechanical properties of Ti and Mo micro-alloyed medium Mn steel. Mater Sci Eng A. 2017;706:1-14. https://doi.org/10. 1016/j.msea.2017.08.110.

3. Haidemenopoulos GN, Aravas N, Bellas I. Kinetics of straininduced transformation of dispersed austenite in low-alloy TRIP steels. Mater Sci Eng A. 2014;615:416-23. https://doi.org/10. 1016/j.msea.2014.07.099.

4. Xia P, Sabirov I, Molina-Aldareguia J, Verleysen P, Petrov R. Mechanical behavior and microstructure evolution of a quenched and partitioned steel during drop weight impact and punch testing. Mater Sci Eng A. 2018;737:18-26. https://doi. org/10.1016/j.msea.2018.09.015.

5. Timokhina IB, Hodgson PD, Pereloma EV. Effect of microstructure on the stability of retained austenite in TransformationInduced-Plasticity steels. Metall Mater Trans A. 2004;35:233141. https://doi.org/10.1007/s11661-006-0213-9.

6. Suh DW, Kim SJ. Medium Mn transformation-induced plasticity steels: Recent progres and challenges. Scr Mater. 2017;126:637. https://doi.org/10.1016/j.scriptamat.2016.07.013.

7. Wang J, Van Der Zwaag S. Stabilization mechanisms of retained austenite in transformation-induced plasticity steel. Metall Mater Trans A. 2001;32:2001-1529. https://doi.org/10.1007/ s11661-001-0240-5.

8. Sugimoto K, Tanino H, Kobayashi J. Impact toughness of medium-Mn transformation-induced plasticity-aided steels. Steel Res Int. 2015;86:1151-60. https://doi.org/10.1002/srin. 201400585. 
9. De Moor E, Matlock DK, Speer JG, Merwin M. Austenite stabilization through manganese enrichment. Scr Mater. 2011;64:185-8. https://doi.org/10.1016/j.scriptamat.2010.09. 040.

10. Jimenez-Melero E, Van Dijk N, Zhao L, Sietsma J, Offerman S. Martensitic transformation of individual grains in low-alloyed TRIP steels. Scr Mater. 2007;55:6713-23. https://doi.org/10. 1016/j.scriptamat.2006.10.041.

11. Shen YF, Qiu LN, Sun X, Zuo L, Liaw PK, Raabe D. Effects of retained austenite volume fraction, morphology, and carbon content on strength and ductility of nanostructured TRIPassisted steels. Mater Sci Eng A. 2015;636:551-64. https://doi. org/10.1016/j.msea.2016.11.017.

12. Sugimoto K, Misu M, Kobayashi M, Shirasawa H. Effects of second phase morphology on retained austenite morphology and tensile properties in a TRIP-aided dual phase steel sheet. ISIJ Int. 1993;33:775-82. https://doi.org/10.2355/isijinternation al.33.775.

13. Tan X, Ponge D, Lu W, Xu Y, He H, Yan J, Wu D, Raabe D. Joint investigation of strain partitioning and chemical partitioning in ferrite-containing TRIP-assisted steels. Acta Mater. 2020;186:374-88. https://doi.org/10.3390/met9070771.

14. Li X, Wei L, Chen L, Zhao Y, Misra RDK. Work hardening behavior and tensile properties of a high-Mn damping steel at elevated temperatures. Mater Charact. 2018;144:575-83. https://doi.org/10.1016/j.matchar.2018.07.036.

15. Gronostajski Z, Niechajowicz A, Kuziak R, Krawczyk J, Polak S. The effect of the strain rate on the stress- strain curve and microstructure of AHSS. J Mater Process Technol. 2017;242:246-59. https://doi.org/10.1016/j.jmatprotec.2016.11.023.

16. Kim H, Lee J, Barlat F, Kim D, Lee MG. Experiment and modeling to investigate the effect of stress state, strain and temperature on martensitic phase transformation in TRIP-assisted steel. Acta Mater. 2015;97:435-44. https://doi.org/10.1016/j.actamat. 2015.06.023.

17. Pereira MP, Rolfe BF. Temperature conditions during 'cold' sheet metal stamping. J Mater Process Technol. 2014;214:1749-58. https://doi.org/10.1016/j.jmatprotec.2014.03.020.

18. Rusinek A, Klepaczko JR. Experiments on heat generated during plastic deformation and stored energy for TRIP steels. Mater Des. 2009;30:35-48. https://doi.org/10.1016/j.matdes.2008.04.048.

19. Rana R, De Moor E, Speer JG, Matlock DK. On the importance of adiabatic heating on deformation behavior of medium-manganese sheet steels. JOM. 2018;70:706-13. https://doi.org/10.1007/ s11837-018-2779-2.

20. Jabłońska MB, Kowalczyk K. Microstructural aspects of energy absorption of high manganese steels. Procedia Manuf. 2019;27:91-7. https://doi.org/10.1016/j.promfg.2018.12.049.

21. Krizan D, De Cooman BC. Analysis of the strain-induced martensitic transformation of retained austenite in cold rolled microalloyed TRIP steel. Steel Res Int. 2008;79:513-22. https://doi.org/ 10.1002/srin.200806160.

22. De Cooman BC. Structure - properties relationship in TRIP steels containing carbide-free bainite. Solid State Mater Sci. 2004;8:285-303. https://doi.org/10.1016/j.cossms.2004.10.002.

23. Grajcar A, Woźniak D, Kozłowska A. Non-metallic inclusions and hot-working behaviour of advanced high-strength mediumMn steels. Arch Metall Mater. 2016;61:811-20. https://doi.org/ 10.1515/amm-2016-0137.

24. ASTM E8/E8M-13a: Standard Test Methods for Tension Testing of Metallic Materials, ASTM International, West Conshohocken, 2013.

25. ASTM E975-3: Standard Practice for X-ray Determination of Retained Austenite in Steel with Near Random Crystallographic Orientation, ASTM International, West Conshohocken, 2013.

26. Dyson DJ, Holmes B. Effect of alloying additions on the lattice parameter of austenite. J Iron Steel Int. 1970;5:469-74.
27. Pereloma EV, Gazder AA, Timokhina IB, Retained austenite: Transformation-Induced Plasticity. Encyclopedia of Iron, Steel, and Their Alloys, Taylor and Francis, New York, 2016.

28. Hojo T, Kobayashi J, Kochi T, Sugimoto K. Effects of thermomechanical processing on microstructure and shear properties of 22SiMnCrMoB TRIP-aided martensitic steel. Iron Steel Technol. 2015;12:102-10.

29. Mirshekari B, Zarei-Hanzaki A, Barabi A, Moshiri A, Abedi HR, Lee SJ, Fujii H. Optimizing the austenite stability in a ferritic lightweight steel through thermomechanical processing. Mater Charact. 2020;166: 110367. https://doi.org/10.1016/j.matchar. 2020.110367.

30. Grajcar A, Kilarski A, Kozłowska A, Radwański K. Microstructure evolution and mechanical stability of retained austenite in thermomechanically processed medium-Mn steel. Materials. 2019. https://doi.org/10.3390/ma12030501.

31. Sun B, Fazeli F, Scott C, Guo B, Aranas C, Chu X, Jahazi M, Yue $\mathrm{S}$. Microstructural characteristics and tensile behavior of medium manganese steels with different manganese additions. Mater Sci Eng A. 2018;729:496-507. https://doi.org/10.1016/j.msea.2018. 04.115.

32. Vieira I, Klemm-Toole K, Buchner E, Williamson DL, Findley $\mathrm{KO}$, De Moor E. A dilatometric study of tempering complemented by Mossbauer spectroscopy and other characterization techniques. Sci Rep. 2017;7:17337. https://doi.org/10.1038/ s41598-017-17654-x.

33. Hunkel M, Dong J, Epp J, Kaiser D, Dietrich S, Schulze V, Rajaei A, Hallstedt B, Broeckmann C. Comparative study of the tempering behavior of different martensitic steels by means of in-situ diffractometry and dilatometry. Materials. 2020;13:5058. https:// doi.org/10.3390/ma13225058.

34. Garcia de Andres C, Cavallero FG, Capdevila C, Alvarez LF. Application of dilatometric analysis to the study of solid-solid phase transformation in steels. Mater Character. 2002;48:101-11. https://doi.org/10.1016/S1044-5803(02)00259-0.

35. Sente software Ltd. A collection of free downloadable papers on the development and application of JMatPro. 2020.

36. Zhang M, Li L, Ding J, Wu Q, Wang YD, Almer J, Guo F, Ren Y. Temperature-dependent micromechanical behavior of mediumMn transformation-induced-plasticity steel studied by in situ synchrotron X-ray diffraction. Acta Mater. 2017;141:294-303. https:// doi.org/10.1016/j.actamat.2017.09.030.

37. Rong T, Lin L, De Cooman BC, Xi-chen W, Peng S. Effect of temperature and strain rate on dynamic properties of low silicon TRIP steel. J Iron Steel Res Int. 2006;13:51-6. https://doi.org/10. 1016/S1006-706X(06)60061-7.

38. Xu N, Jiang $\mathrm{H}, \mathrm{Wu} \mathrm{X}$. TEM and HRTEM study of influence of thermal cycles with stress on dynamic recrystallization in Ti46Al8Nb1B during creep. Micron. 2008;39:1210-5. https:// doi.org/10.1016/j.micron.2007.11.013.

39. Su D, Zhu Y. Scanning moire fringe imaging by scanning transmission electron microscopy. Ultramicroscopy. 2010;110:229-33. https://doi.org/10.1016/j.ultramic.2009.11.015.

40. Zaefferer S, Ohlert J, Bleck W. A study of microstructure, transformation mechanisms and correlation between microstructure and mechanical properties of a low alloyed TRIP steel. Acta Mater. 2004;52:2765-78. https://doi.org/10.1016/j.actamat.2004. 02.044 .

Publisher's Note Springer Nature remains neutral with regard to jurisdictional claims in published maps and institutional affiliations. 